\title{
“Manda Quem Pode", a violência como ressonância do crime de pedofilia
}

\author{
"Shut Up and Dance", violence as the \\ resonance of the crime of pedophilia
} "Cállate y baila", la violencia como
resonancia del crimen de pedofilia

TELMA BRITO ROCHA ${ }^{a}$

\section{Resumo}

Os crimes praticados no ciberespaço, entre eles, a pedofilia, ganham relevância significativa no momento em que vivemos a amplitude e a intensificação de interações on-line. O presente texto tem como objetivo analisar o episódio "Manda Quem Pode", da série Black Mirror que produz um pensamento crítico sobre a violência, a cultura, o social e o político na contemporaneidade. Através dessa história ficcional, analiso a pedofilia on-line, e a ressonância da violência virtual, bem como, os cuidados on-line que devemos ter com a navegação de crianças e adolescentes na rede internet. Os discursos sobre a violência apresentados no episódio nos revelam com clareza o poder das redes digitais, na disseminação e no aumento da visibilidade de um acontecimento. A proposta de desenvolvimento do trabalho foi apoiada na abordagem qualitativa, por meio de um estudo de caso, dos personagens, seus discursos, situações, a violência e a pedofilia no episódio.

Palavras-chaves: Black Mirror. Pedofilia. Cuidados on-line.

\begin{abstract}
The crimes practiced in cyberspace, among them, pedophilia, gain significant relevance at the moment we live the breadth and intensification of online interactions. The present text aims to analyze the episode "Shut Up and Dance", from "Black Mirror" that produces critical thinking about violence, culture, social and political in contemporary times. Through this fictional story, I analyze online pedophilia, and the resonance of virtual violence, as well as the online care we should have with the navigation of children and adolescents on the internet. The speeches on violence presented in the episode reveal the power of digital networks in the dissemination and increase of the visibility of an event. The proposal
\end{abstract}

\footnotetext{
a Universidade Federal da Bahia, Salvador, BA, Brasil. Doutora em Educação, e-mail: telmabr@gmail.com 
of development of the work was supported by a qualitative approach, through a case study, of the characters, their speeches, situations, violence, and pedophilia in the episode.

Keywords: Black Mirror. Pedophilia. Online care.

\section{Resumen}

Los crímenes practicados en el ciberespacio, entre ellos, la pedofilia, ganan relevancia significativa en el momento en que vivimos la amplitud y la intensificación de interacciones en línea. El presente texto tiene como objetivo analizar el episodio "Cállate y baila", de la serie "Black Mirror" que produce un pensamiento crítico sobre la violencia, la cultura, lo social y lo político en la contemporaneidad. A través de esa historia ficcional, analizo la pedofilia online, y la resonancia de la violencia virtual, así como los cuidados en línea que debemos tener con la navegación de niños y adolescentes en la red internet. Los discursos sobre la violencia presentados en el episodio nos revelan con claridad el poder de las redes digitales, en la diseminación y en el aumento de la visibilidad de un acontecimiento. La propuesta de desarrollo del trabajo fue apoyada en el abordaje cualitativo, por medio de un estudio de caso, de los personajes, sus discursos, situaciones, la violencia y la pedofilia en el episodio.

Palabras claves: Black Mirror. Pedofilia. Cuidado en línea.

\section{Introdução}

Redes sociais digitais, espaços que reúnem um conjunto de pessoas (ou organizações) conectadas virtualmente por relações sociais, como amizades, atividades, ou intercâmbio de informações, se caracterizam também como meios que promovem formatos de exposição da vida íntima e privada.

A sociedade, as individualidades em rede, essa exposição de si, facilitou a execução e a disseminação de práticas ilícitas, delitos existentes no mundo offline, agora potencializados pela comunicação "todos com todos" na rede mundial de computadores.

Sendo assim, a criminalidade não é um fenômeno alheio a essas transformações. Como a rede é um espaço de socialização como qualquer outro, mediado por ações de indivíduos que fazem parte dela, a violação dos direitos humanos também ocorre neste espaço, agora com características sofisticadas por meio das tecnologias.

Os crimes praticados no ciberespaço, entre eles a pedofilia, ganham relevância significativa no momento em que vivemos a amplitude e organização em rede. Neste sentido, a escola e toda sociedade deve estar atenta ao assédio sexual, à pornografia infantil, e o comércio e divulgação 
desses materiais, até o tráfico e exploração sexual de crianças e adolescentes, para que possamos inibir essas ações, cobrando ainda políticas governamentais de combate.

Com o aumento do acesso à rede Internet, o serviço de streaming também se desenvolveu, hoje o usuário da rede não depende mais de um horário fixo para assistir a um filme. O streaming revolucionou a indústria do entretenimento e os hábitos dos espectadores mundo afora. Os serviços on-line de vídeo, como da Netflix, Amazon, entre outros, crescem constantemente pelo mundo. Cresce, também, o número de espectadores, bem como o interesse de pesquisadores em utilizar os discursos desses roteiros para interpretar a cultura contemporânea, comportamento, interações, sociabilidades a partir das tecnologias digitais.

Essas séries, veiculam, constroem discursos e produzem significados. Como afirma Macedo (2009, p. 112), discurso é “[...] um fenômeno social e constitui um dos vínculos mais importantes de produção de sentidos no interior de uma sociedade, com uma importante função de se constituir ideologicamente".

Inspirada nessas concepções, este artigo busca analisar os crimes praticados no ciberespaço, entre eles, a pedofilia, através de discursos produzidos no episódio "Manda Quem Pode" , cujo protagonista Kenny é um adolescente inglês que trabalha numa lanchonete como garçom; após ser filmado em momento privado em que via imagens íntimas de crianças em seu computador, ele passa a cometer outros crimes a mando de justiceiros on-line. O episódio releva a violência como ressonância de outras violências, por meio de vingança on-line, justiceiros da internet que se propõem a combater esses crimes cometendo outros crimes.

\section{Metodologia}

A proposta de desenvolvimento do trabalho foi apoiada na abordagem qualitativa, por meio de um estudo de caso dos personagens, seus discursos, situações, a violência e a pedofilia no episódio. Segundo Marlí André (2013, p. 97), “[...] o estudo de caso começa com um plano muito aberto, que vai se delineando mais claramente à medida que o estudo avança". Assim, a opção foi analisar elementos selecionados da série, à luz dos conceitos discutidos no referencial teórico-metodológico, procurando estabelecer uma relação entre os conceitos teóricos e os discursos de violência produzidos na narrativa. 
O termo discurso aqui é tomado a partir da concepção foucaultiana, na qual o discurso não pode se resumir ao mero ato de fala. Para o autor, os discursos não estão localizados num campo de exterioridade em relação aos objetos que, supostamente, eles descrevem. Em sua afirmação, os discursos se instituem como “[...] práticas que formam sistematicamente os objetos de que falam" (FOUCAULT, 2008, p. 55).

Os discursos são produzidos por meio de diferentes técnicas, tecnologias e estratégias. A articulação de técnicas de dominação e as técnicas de si produzem as subjetividades. Segundo Woodward (2000, p. 55), subjetividade é a compreensão que temos do nosso eu. O termo envolve os pensamentos e as emoções conscientes e inconscientes que constituem nossas concepções sobre "quem nós somos". A subjetividade envolve nossos sentimentos e pensamentos mais pessoais. Entretanto, vivemos nossa subjetividade em um contexto social no qual a linguagem e a cultura dão significado à experiência que temos de nós mesmos e no qual adotamos uma identidade.

Assim, os saberes desenvolvidos sobre si para conhecer os processos de objetivação e subjetivação são onde se encontram entrelaçados as práticas sociais, produtoras de “jogos de verdade".

Para Foucault (2000), essa “verdade” está circularmente ligada a sistemas de poder, que a produzem e a apoiam, assim como aos efeitos de poder que ela induz e que a reproduzem. Dessa forma, não é apenas em relação aos discursos "dominantes" ou "dominadores" de qualquer sociedade que faz sentido falar de regimes de verdade. Por meio dos discursos apresentados na narrativa, se pretende questionar e criticar o comportamento desses personagens praticantes de crimes virtuais, analisando como a sociedade conduz suas próprias vidas a partir das ameaças via mensagens instantâneas, pois a história ficcional revela com clareza o aumento da visibilidade de um acontecimento por meio das tecnologias. Os discursos produzidos no episódio devem tomar em consideração os contextos que são produzidos. A observação e interpretação das relações sociais nos ajudam a entender, por conseguinte, a sociedade atual.

Nesse sentido, conhecer o conceito de violência, a pedofilia neste contexto, e as ressonâncias da violência virtual, bem como discutir os cuidados on-line que devemos ter com a navegação de crianças e adolescentes na rede internet estão entre os objetivos a seguir. 


\section{A violência}

Fenômeno polissêmico e multicausal, apresenta diferentes modalidades e níveis, o que dificulta a elaboração de uma única definição. Na literatura sobre o tema, a violência é apresentada como um fenômeno de grande complexidade, sendo conceituada de diversas maneiras e a partir de distintas perspectivas.

Partindo do significado vocabular, a violência tem sua origem no latim violentia, que significa qualidade de violento, ato violento, ato de violentar, constrangimento físico ou moral, uso da força, coação. Essa definição, no Novo Dicionário Aurélio de Lingua Portuguesa (FERREIRA, 2004), limita-se apenas ao significado semântico da palavra.

Vários estudos em Sociologia, Psicologia e Saúde Pública entendem a violência como um fenômeno socialmente construído. No âmbito dessas teorizações, Franco (1990) afirma que violência é um processo dirigido a certos fins, tendo diferentes causas, assumindo formas variadas e produzindo certos danos, alterações e consequências imediatas ou a longo prazo.

A definição ora apresentada é ampla e dá margem a inúmeras interpretações, a diversos significados do que seria violência, o que pressupõe o reconhecimento da sua complexidade e polissemia.

Corroboram com esse entendimento, Waiselfisz e Maciel (2003), que apontam duas questões que dificultam a definição da violência. A primeira refere-se ao fato de que os significados do termo violência são socialmente construídos, modificando-se de acordo com o momento histórico ou o contexto social. A segunda está relacionada ao fato de que a palavra violência pode se referir a situações bastante diversificadas, tais como a doméstica, juvenil, bélica, contra a criança, simbólica, que se associam a modos de manifestação e de entendimento diferentes.

Por outro lado, Costa (1984, p. 30) define violência como: O emprego desejado da agressividade, com fins destrutivos. Esse desejo pode ser voluntário, deliberado, racional e consciente, ou pode ser inconsciente, involuntário e irracional.

Nesse sentido, a violência ocorre quando há desejos de destruição da parte do algoz. Caracteriza-se pela intencionalidade e está presente em toda ação humana. $\mathrm{O}$ autor ainda admite que a violência se institui a partir dos conflitos instaurados no âmbito da cultura e entende a 
violência “[...] como uma particularidade do viver social, um tipo de negociação, que, através do emprego da força ou da agressividade, visa a encontrar soluções para conflitos que não se deixam resolver pelo diálogo e pela cooperação" (COSTA, 1984, p. 47).

Essa contestação permite compreender que existe uma transição do estado da natureza para o estado da cultura, mostrando a necessidade de compreensão da violência como um fenômeno socio-histórico e cultural que emerge a partir do desejo.

\section{A pedofilia no contexto da violência}

A palavra pedofilia é composta por dois termos em latim: PEDO = criança e FILIA $=$ amor, apego, gosto, atração. É um dos casos de abuso sexual, praticado por um indivíduo pedófilo que possui desejo sexual por crianças e adolescentes. Suas práticas se constituem de ações que acontecem pela utilização de pressão, intimidação, coerção, chantagem, suborno, manipulação, ameaça ou qualquer outro mecanismo que anule ou limite a vontade pessoal. Ela ainda pode ocorrer por diversas formas: ligações telefônicas obscenas, ofensa ao pudor e voyeurismo, imagens pornográficas, relações ou tentativas de relações sexuais, incestos ou prostituição de menores.

Um tipo de crime que antes da "Era da Internet" existia como um problema com focos individualizados ou restritos de difícil punição. Um crime que envolvia o abuso de menores de forma sexual e/ou pornográfica através de fotografias, filmes e vídeos distribuídos através de meios analógicos e, portanto, mais lentos e de alcance limitado. Segundo Silva Sánchez (2002), teórico do Direito Penal, o progresso da tecnologia propiciou a criação de novos tipos de delinquência e, ao mesmo tempo, permitiu que as criminalidades tradicionais encontrassem outros campos de atuação.

Hoje, muitas pessoas estão vivenciando problemas reais resultantes de conflitos virtuais, tais como: invasão de privacidade, ofensas à imagem, honra, intimidade, além de ilícitos como estelionato, contrabando, roubo, formação de quadrilha, terrorismo, lavagem de dinheiro e, propriamente, a pedofilia. Sobre essa última, Hisgail (2007, p. 28) destaca a questão do comércio que estruturam as redes de pedofilia no mundo: 
No mercado do sexo, a troca de vídeos e revistas com atores mirins e anúncios dissimulados, numa linguagem preenchida por códigos que apenas os usuários conhecem, figura como uma atividade rentável e lucrativa, abastecida por produtos de alto valor comercial.

Com a internet, a produção, utilização, exibição, comercialização de material (fotos, vídeos) com cenas de sexo explícito envolvendo crianças e adolescentes tem distribuição e alcance imaginável. Através dessa rede é possível “contratar” serviços de exploradores sexuais, fazer turismo sexual ou mesmo efetivar o tráfico de menores e aliciá-los para práticas de abusos sexuais. É possível verificar que as redes de pedofilia viraram comércio lucrativo no mundo inteiro, articulam ainda suas ações a tráficos de drogas e lavagem de dinheiro.

Mas o que faz essas redes desafiarem os direitos humanos, e os sujeitos que fazem parte dela, e desprezar certos direitos elementares da convivência humana? Autoras como Fani Hisgail, que analisa de forma psicanalítica para responder a essa pergunta, acredita que se trata de uma questão psicopatológica, pois o pedófilo na sua subjetivação coloca a criança no lugar de um objeto de gozo para uma libido errante.

A pedofilia é um ato violento e impactante, uma prática em que um sujeito recusa as leis, simbólica e social, colocando em ato uma fantasia que não apresenta escolha ao outro, no entanto, é fundamental sairmos da perplexidade que nos absorve e analisar conjuntamente com a dimensão psicológica o aspecto jurídico que contribui para dar contornos legais a esse recorte psicopatológico que é a pedofilia.

O art. 227 da Constituição da República diz que é dever da família, da sociedade e do Estado colocar as crianças e os adolescentes a salvo de toda forma de negligência, discriminação, exploração, violência, crueldade e opressão. E o $\int 4^{\circ}$ desse mesmo artigo obriga o Estado a punir severamente o abuso, a violência e a exploração sexual da criança] e do adolescente.

Nas duas últimas décadas, vimos um esforço do governo brasileiro em modificar a legislação para coibir crimes na internet. Assim, em 25 de novembro de 2008 o ex-Presidente Luiz Inácio Lula da Silva sancionou a Lei n. 11.829, que alterou os artigos 240 e 241 da Lei no 8.069, de 13 de julho de 1990 — Estatuto da Criança e do Adolescente, para aprimorar o combate à produção, venda e distribuição de pornografia infantil, bem como criminalizar a aquisição e a posse de tal material e outras condutas relacionadas à pedofilia na internet. 
Agora a legislação se torna mais eficiente em caso de uso da rede internet para prática desse crime. A nova redação dada aos artigos 240 e 241, do Estatuto da Criança e do Adolescente, prevê a punição também a quem armazena material pornográfico infantil e aos provedores que, uma vez notificados sobre o conteúdo de sites com esse material, não desabilitem o acesso. A punição para quem produz ou usa cenas de pornografia infantil passa de dois a seis anos de reclusão para quatro a oito anos. São previstas ainda punições a quem oferece, troca ou transmite pornografia infantil (três a seis anos) por meio de sistema de informática ou mesmo para quem armazena esse tipo de material (um a quatro anos).

\section{Notas sobre o episódio “Manda Quem Pode"}

Londres, sec. XXI. Em uma pacata lanchonete da cidade, Kenny, é um adolescente inglês e trabalha como garçom. Ao limpar uma mesa que acabara de vagar, Kenny percebe um brinquedo que fora esquecido por uma garotinha acompanhada de sua mãe. Rapidamente ele corre e consegue alcançá-las a tempo de devolver o brinquedo e, como agradecimento, ganha um belo sorriso da garotinha.

Esta é uma das cenas iniciais do $3^{0}$ episódio da $3^{a}$ temporada da premiada série Black Mirror. Trata-se de uma série britânica de ficção científica e distopia, criada pelo jornalista e apresentador Charlie Brooker. A trama — de episódios independentes — é centrada em temas que abordam a sociedade contemporânea e sua relação com o avanço das tecnologias digitais. Os capítulos são ambientados em um presente alternativo - paralelo ao real - e em um futuro não muito distante. Sua estreia foi em 4 de dezembro de 2011, ganhando notoriedade apenas em 2015, quando foi comprada pelo serviço de streaming Netflix. Hoje, a série conta com 4 temporadas — totalizando 19 episódios, e neste artigo falaremos somente sobre o episódio em questão.

O enredo continua nos mostrando que Kenny (Alex Lawther) sofre bullying dos colegas de trabalho, ele vive com a mãe e a irmã — com quem não aceita dividir o computador. Certo dia, ao chegar em casa e perceber que a caçula pegou seu laptop emprestado sem permissão, o garoto instala um removedor de malware na máquina e não percebe quando sua webcam é crackeada. A partir de então, a sofrida saga de Kenny se inicia. 
Após ser filmado se masturbando, Kenny recebe um e-mail com o vídeo que compromete sua integridade íntima seguido da seguinte mensagem "mande o número do seu celular ou vazaremos o vídeo para todos os seus contatos”. Acuado, o garoto cede à chantagem e, já no seu aparelho de telefone móvel, recebe outro comando "deixe seu celular carregado e o GPS ligado, e aguarde até ser chamado".

No dia seguinte, Kenny recebe uma mensagem de texto mandando ele se dirigir, imediatamente, a um determinado estacionamento da cidade e, ao chegar no local, toma posse de uma encomenda de outra personagem que também está sendo chantageada. Prosseguindo, Kenny deverá entregar a encomenda — um bolo — em um quarto de hotel; onde conhece Hector (Jerome Flynn) e juntos terão que cumprir outra missão a fim de evitarem que suas informações comprometedoras sejam divulgadas.

Dentro do bolo eles encontram um pacote que contém uma arma de fogo, óculos e um boné. A arma e os disfarces devem ser utilizados para assaltar um banco, ficando a cargo deles decidir quem será o assaltante e quem esperará no carro para comandar a fuga. Kenny aceita ser o assaltante. De volta ao carro, com o dinheiro do assalto em mãos, eles despistam a polícia e se direcionam para a entrada de uma reserva florestal e aguardam as novas ordens do chantagista.

A Hector, é dada a missão de destruir o carro que foi utilizado no roubo e voltar para casa. Kenny, por sua conta, deverá seguir há um determinado local no meio da floresta levando o dinheiro do roubo. Lá, ele encontra outra vítima de chantagem. Eles iniciam uma conversa reveladora sobre os motivos pelo qual estão sendo chantageados. É neste momento que o episódio choca seus espectadores. Até então, acreditava-se que Kenny apenas tinha sido filmado se masturbando. Porém, a questão maior era o que o adolescente estava vendo ao praticar o ato: pornografia infantil. Neste momento, descobre-se que Kenny não é apenas um garoto se masturbando, mas sim um pedófilo, tanto quanto o outro personagem que esperava por ele no meio da floresta.

Seguindo, Kenny e a outra personagem (Paul Bazely), um homem magro de meia idade, deverão lutar até a morte, ficando como prêmio para o sobrevivente o dinheiro do assalto. Um drone com uma câmera está transmitindo toda a luta para o chantagista.

As cenas finais do episódio mostram Kenny saindo da floresta todo machucado e ensanguentado, segurando o dinheiro do assalto. Logo, se supõe que ele venceu a luta e, além de 
pedófilo e assaltante, ele agora também é um assassino. O adolescente recebe uma ligação de sua mãe, dizendo que viu o vídeo dele se masturbando e as imagens das crianças que ele estava acessando. A partir daí todos os segredos — crimes — das vítimas de chantagens são revelados pelo chantagista, perpassando por adultério, racismo e pedofilia, independente deles terem cumprido às ordens ou não. Kenny é preso por dois policiais e o episódio se encerra.

\section{A pedofilia e a ideia de justiça com vingança on-line}

Importante análise deste trabalho reside na violência como ressonância de outras violências, e na justiça como ideia de vingança on-line. O episódio "Manda Quem Pode", evidencia que pedófilos, ao mesmo tempo que são criminosos, são também vítimas, quando reféns de justiceiros ou vingadores on-line. Por outro lado, os pedófilos, motivados pelo instinto de sobrevivência, em obediência aos vingadores, cometem novos crimes.

A reprodução da violência produz efeitos sobre suas vidas, envolvendo-os numa teia de novos casos de violência. Este aspecto da série corrobora para a compreensão de que as práticas de violência também são ressonâncias de outras violências. Embora não percebam suas ações como violência, as vítimas dos justiceiros on-line apostam no instinto de sobrevivência, acreditam que estão fazendo justiça com a vingança on-line.

Será que fazemos justiça com violência, violência psicológica, chantagem e vingança online? O chantagista também não é um criminoso? Será que suas motivações foram realmente "fazer justiça"?

É notório que as vítimas de chantagem presentes no episódio cometeram crimes e o personagem principal praticou crime de pedofilia. Entretanto, concordar e praticar a "justiça com as próprias mãos" como o chantagista — anônimo — é perigoso. Combater violência com outra violência também é crime e um caminho que nos leva para a barbárie social. A "pornografia da vingança - que equivale a divulgação de fotos e ou vídeos íntimos na internet, sem o consentimento da protagonista do conteúdo, tornou-se uma prática comum no ambiente virtual.

Pode-se ainda fazer um paralelo da "justiça com as próprias mãos" com a incapacidade de pensar e refletir sobre o ato a ser praticado. Um sujeito, ao ceifar a vida de outrem por esse ter assassinado brutalmente seu ente querido, acaba determinando uma equidade de ação, ou seja, ambos cometeram um crime de homicídio e, portanto, devem responder legalmente por isso. 
Nos parece que a banalização da violência na contemporaneidade funciona como um aliado a sua perpetuação. Para Costa (1984), a ideia de que somos "instintivamente violentos" acaba por nos resignar a um destino, admitindo uma natureza violenta (COSTA, 1984, p. 34) Assim, se há uma violência inerente ao homem, as múltiplas manifestações violentas estariam justificadas, e por isso mesmo não haveria possíveis saídas para a violência.

Existem teorias que partem da premissa de que a violência é natural e inevitável, substituem a ideia de processo social e histórico pelo conceito de "agressão", que provém da biologia, genética e medicina. Nelas, a categoria agressividade é entendida como parte do instinto de sobrevivência e forma natural de reação dos animais em certas condições e situações, tendo, portanto, conotação de neutralidade e naturalidade. Ao partilhar da crença na "instintiva agressividade humana", acabam subordinando, a priori, os componentes da atividade humana aos instintos biológicos.

Esse ponto de vista é também particularizado na obra de Freud O mal-estar da civiliz̧ação, de 1929, que fala sobre o problema dos instintos destrutivos humanos, considerando-os responsáveis pelo mal-estar da civilização.

Costa (1984, p. 24), partindo da leitura freudiana, acrescenta que a satisfação desses impulsos destrutivos ainda é naturalmente facilitada pela mistura de outros motivos de natureza erótica e idealista. Segundo o autor:

Quando lemos sobre as atrocidades do passado, amiúde é como se os motivos idealistas servissem apenas de escusa para os desejos destrutivos; e às vezes - por exemplo, no caso das crueldades da Inquisição -, é como se os motivos idealistas tivessem assomado a um primeiro plano na consciência, enquanto os destrutivos thes emprestassem um reforço inconsciente (COSTA, 1984, p. 24)

Nesse sentido, a violência não tem outra causa senão a satisfação dos impulsos e desejos destrutivos do homem. Esses motivos são geralmente racionalizados (no sentido psicanalítico), e buscam justificar, perante a consciência, a existência dessa destrutividade.

Assim, observamos o instinto de sobrevivência de Kenny e o personagem Paul Bazely, que lutam até a morte, sob a ordem do justiceiro on-line que assiste através câmera instalada em drone. A agressividade aqui se constitui numa disposição instintiva, primitiva e autônoma do ser humano. 
Se tratando desta multicausalidade, no episódio a violência psicológica estrutura as ações em relação aos praticantes de crimes on-line. Segundo Evans (1996), violência psicológica se trata de atitudes de abuso de poder, de controle sobre o outro e envolve pelo menos três dimensões:

[...] poder - no sentido de "resolver pelo outro" e estão explicitados nas seguintes palavras: decidir, ir contra, impedir, acusar, dar ordens, mandar fazer, causar insegurança, ameaçar; humilhação: "ridicularizar, chamar por palavrões, desaprovar"; coisificação do outro: "esquecer e desprezar, não levar em conta o valor/ desejo/ necessidade do outro, cometer injustiça" (EVANS, 1996, p. 81)

A violência psicológica praticada pelo justiceiro on-line, se pauta em chantagem, inclui ação de controle total em relação aos atos dos praticantes de crimes de pedofilia, usa do seu poder para dar ordens que acabam por levar os pedófilos a cometerem outros crimes, observa-se humilhações, caracterizada pelo modo de comunicar do agressor, acompanhada de ameaças, atos denominados de violência verbal também transmitidas por meio de mensagens via celular anonimas.

A possibilidade de anonimato na internet é um elemento que encoraja as atitudes agressivas. Quando o justiceiro on-line ameaça dar visibilidade em rede das imagens dos pedófilos, ele está escondido no anonimato, ainda que saibamos que não existe privacidade na internet. Esse anonimato temporário, porque a identidade off-line dos autores das mensagens ainda não foi descoberta, empodera, significativamente, os discursos que apoiam a prática de violência virtual. Como afirma, Bruno (2006, p. 4):

A convergência da informática com as telecomunicações criou uma situação em que o campo de comportamentos, ações e comunicações dos indivíduos muitas vezes coincide com os próprios sistemas de coleta, registro e distribuição de informação. As mesmas tecnologias que ampliam as possibilidades de emissão, acesso e distribuição da informação tornam-se instrumentos de vigilância e controle; as mesmas tecnologias que possibilitaram o anonimato nas trocas sociais $e$ comunicacionais mostram-se eficientes instrumentos de identificação.

Para Ortega e Jäger (2007), a violência na internet tem efeitos graves para os que dela sofrem e que são diferentes daquelas violências decorrentes de interação face a face, remetendo a uma dinâmica própria. As vítimas não encontram lugares seguros onde possam cortar o contato com os agressores e, além disso, a agressão pode acontecer a qualquer momento, e os espectadores do ato agressivo se multiplicam de maneira surpreendente. Ou seja, a palavra escrita ou a imagem tende a causar um dano maior, pois podem ser lidas ou vistas várias vezes. Neste caso, é possível perceber durante todo episódio que Kenny, Hector e Paul, são extremamente 
impactados psicologicamente pelas mensagens que recebem ao celular, apreensão, o medo, nervosismo, a instabilidade emocional é evidente em seus personagens.

Uma das peculiaridades da violência contemporânea é sua excessiva visualização, que nos informa o mundo através do que vemos e ouvimos. Nesse sentido, o mundo espetacularizado, violento e tecnificado, cujo retrato, construído e difundido pelos sistemas de mídias, constitui um elemento extremamente importante do universo de socialização das novas gerações.

No final do episódio, Kenny e Paul Bazely chegam ao ponto alto do controle e visibilidade, lutam até a morte, e um drone com uma câmera está transmitindo tudo para o justiceiro on-line.

Como podemos ver, atualmente, não são apenas as instituições disciplinares que vigiam os indivíduos, não só esses espaços isolam e imobilizam indivíduos em espaços de confinamento, tornando seus atos descritíveis, mensuráveis, a partir de registro e análise.

Vemos hoje uma espécie de Cibervoyeur que vigia e pode gravar o que você faz. Circuitos internos de TV, câmeras, chips, Youtube, redes sociais, programas computacionais de coleta e processamento de informação expõem as ações e comportamentos de inúmeros indivíduos a uma vigilância contínua.

Essas tecnologias se constituem em dispositivos de vigilância, que não mais se estendem aos espaços privados, de empresas, entre outros espaços que usam as câmeras em circuito interno para promoção de segurança, mas esse novo conceito se amplia no ciberespaço, nas interações mediadas pelas tecnologias de modo geral. Essa vigilância tem promovido a exposição e a possibilidade de uso de suas informações de várias pessoas.

A trama de violência que os pedófilos se envolveram, com a ação do justiceiro on-line, só foi possível se desenvolver por conta dos dispositivos de vigilância, instalados em seus computadores para capturar imagens e mensagens íntimas dos próprios usuários da rede. Segundo Fernanda Bruno, (2016, p. 2), “os rastros digitais na internet não é uniforme”. Para a autora, esses rastros são inscritos de acordo com camadas informacionais e são mais ou menos visíveis, seus vínculos identificáveis.

\section{Atitudes educativas contra pedofilia}


Talvez não seja possível controlar completamente a propagação e a inter-relação entre os praticantes de pedofilia, mas certamente há como prevenir as crianças dos perigos a que estão expostas. É fundamental que pais e/ou responsáveis e educadores aprendam mais sobre internet, conhecendo as possibilidades de seu uso.

Portanto, ações de sensibilização de pais e professores, articulação da esfera governamental e ONGs, podem contribuir para proteger crianças e adolescentes da exposição a conteúdos que podem ser lesivos ao seu desenvolvimento psicossocial.

Não se pode e nem se deve privar as crianças do uso das tecnologias digitas, mas tem-se a obrigação de ensiná-los a navegar na rede de maneira segura. Apesar de Black Mirror ser uma obra de ficção, pode-se perceber que — de acordo com os dados supracitados — o episódio retrata uma realidade rotineira em nosso país e no mundo. Existem diversos usuários da rede internet, de todas as idades, praticando pedofilia.

Dicas para os pais e/ou responsáveis, ao permitirem a participação de crianças no mundo virtual, monitorem o tempo que ficam on-line, inclusive limitando o uso da rede; este tempo deve ser dosado com outras atividades físicas, escolares, culturais; estabeleça combinados com eles, criando regras de uso, como acesso a sites. As informações postadas nas redes sociais devem ser acompanhadas. É importante conhecer os perfis de outras crianças que eles adicionam. Se não há familiares nas fotos, nos posts ou nos depoimentos, e as comunicações são apagadas, desconfie. A mesma atitude dever ser feita em relação aos comunicadores instantâneos, WhatsApp, entre outros.

Se a criança possuir perfil em redes sociais, é recomendado colocar no perfil dele o link do seu próprio perfil ou seu e-mail pessoal, com um aviso de que está monitorando diariamente os contatos das crianças. Assim os pedófilos saberão que aquele perfil possui acompanhamento de um adulto. Isso também facilitaria que outros usuários entrem em contato com você caso alguém queira alertá-lo sobre problemas.

Usar bloqueadores de site apenas não é a solução mais eficiente, em alguns casos as crianças e adolescentes sabem como desinstalá-los, o mais importante é criar um clima de diálogo e confiança. Instrua a não divulgar dados pessoais, endereço de escola, e-mails, entre outras informações. Manter o computador numa área comum da casa é outro fator importante. Se encontrar material ofensivo e violento, explique às crianças e aos adolescentes o que vai fazer. 
Outro caminho importante, além dos cuidados que devemos ter, é a denúncia de atitudes e condutas ilegais. Existe por parte do poder governamental e não governamental, intuições tais como, conselhos tutelares, varas da infância e da juventude em sua cidade, delegacia de proteção à criança e ao adolescente, em alguns estados. As denúncias ainda podem ser feitas pela internet, nos sites: SaferNet - https://new.safernet.org.br/denuncie/\# ou através do Disque 100, discagem gratuita, de qualquer terminal telefônico fixo ou móvel (celular), recebe e encaminha denúncias de violações de direitos humanos de crianças e adolescentes.

\section{Considerações finais}

O avanço tecnológico e o acesso à internet não devem ser responsabilizados pelo mal que acontece no ciberespaço, pois, atrás de um computador ou smartphone tem um operador humano que manipula as interações. O que precisa ser entendido também é que, não há crime novo no mundo virtual, mas sim a transposição do que já existe na vida off-line. A pedofilia existe bem antes da era da internet.

Embora alguns separem a vida on-line da vida off-line, experimentando identidades diferentes dentro e fora da rede internet, o episódio "Manda Quem Pode", da série Black Mirror, não é diferente, o discurso que aparece no início da narrativa, apresenta Kenny como um garoto normal, que tem pequenos conflitos com a irmã e que parece ter um bom relacionamento com a mãe. Durante o desenvolvimento do episódio, nos deparamos com discursos e situações em que Kenny pratica comportamentos criminosos a partir dos espaços virtuais como ressonância de outras violências.

A vulnerabilidade das crianças no contexto virtual da pornografia deve servir de alerta para a sociedade, aos educadores pais e/ou responsáveis. Por outro lado, é importante destacar que medidas educativas devem ser dirigidas a crianças e adolescentes, bem como, tratamento psicológico para aqueles que praticam a pedofilia. 


\section{Referências}

ANDRÉ, M. O que é um estudo de caso qualitativo em educação? Revista FAEEBA, v. 22, p. 95-104, 2013.

BRASIL. Constituição, 1988. Constituição: República Federativa do Brasil. Brasília: Senado Federal, 1988.

BRASIL, Presidência da República. Lei $N^{o}$ 11.829, de 25 de Novembro de 2008. Altera a Lei no 8.069, de 13 de julho de 1990 - Estatuto da Criança e do Adolescente, para aprimorar o combate à produção, venda e distribuição de pornografia infantil, bem como criminalizar a aquisição e a posse de tal material e outras condutas relacionadas à pedofilia na internet.

BRUNO, F. Dispositivos de vigilância no ciberespaço: duplos digitais e identidades simuladas. Revista Fronteira, São Leopoldo, v. 8, p. 152-159, 2006.

BRUNO, F. Rastrear, classificar, performar. Cienc. Cult., v. 68, n. 1, p.34-38, 2016. DOI: http:/ /dx.doi.org/10.21800/2317-66602016000100012

COSTA, J. F. Violência e psicanálise. Rio de Janeiro: Graal, 1984.

EVANS, P. The verbally abusive relatioship: how to recognize it and how to respond. 2. ed. Massachusetts: Adans Média Corporation, 1996.

FERREIRA, A. B. H. Novo dicionário Aurélio da língua portuguesa. 11. ed. Curitiba: Editora Positivo, 2004.

FOUCAULT, M. Microfísica do poder. 9. ed. Rio de Janeiro: Graal, 2000.

FOUCAULT, M. A arqueologia do saber. 7. ed. Rio de Janeiro: Forense Universitária, 2008.

FOUCAULT, M. Microfisica do poder. 9. ed. Rio de Janeiro: Graal, 2000.

FRANCO, S. La violência: un problema de salud pública que se agrava en la Región. Boletín Epidemiológico de la OPS, v. 11, n. 2, p. 1-7, 1990.

HISGAIL, F. Pedofilia, um estudo psicanalítico. São Paulo: Iluminuras, 2007. p. 126.

MACEDO, R. S. A. Estudos e pesquisas em currículo e formação nos âmbitos do FORMACCE FACED/UFBA: a centralidade da narrativa implicada. MACEDO, E.; MACEDO, R.S.; AMORIM, C. A. (Org.). Discurso, texto, narrativa nas pesquisas em curriculo. Campinas: FE-UNICAMP, 2009. p. 107-113.

ORTEGA, R.; JÄGER, T. Acting against school bullying and violence: the role of media, local authorities and the internet. Landau: Verlag Empirische Pädagogik, 2007.

SILVA SÁNCHEZ, J.-M. A expansão do direito penal: aspectos da política criminal nas sociedades pósindustriais. São Paulo: Revista dos Tribunais, 2002. 
WAISELFISZ, J. J.; MACIEL, M. Revertendo violências, semeando futuros: avaliação do Programa Abrindo Espaços no Rio de Janeiro e em Pernambuco. Brasília: Unesco, 2003.

WOODWARD, K. Identidade e diferença: uma introdução teórica e conceitual. In: SILVA, T. T. (Org.). Identidade e diferença: a perspectiva dos estudos culturais. 6. ed. Petrópolis: Vozes, 2000. 